\title{
TRIVALENT ION CROSS-LINKED AND ACETALATED GELLAN GUM MICROSPHERES OF GLIMEPIRIDE
}

\author{
SUDIPTA DAS*, RIMI DEY \\ Department of Pharmaceutics, Netaji Subhas Chandra Bose Institute of Pharmacy, Chakdaha, West Bengal, India. \\ Email: sudiptapharmacy6@gmail.com
}

Received: 02 February 2020, Revised and Accepted: 09 March 2020

\section{ABSTRACT}

Objectives: A novel formulation was developed with glimepiride loaded trivalent ion $\mathrm{Al}^{+3}$ cross-linked and acetalated gellan gum microspheres.

Methods: The glimepiride loaded microspheres were formulated using sodium alginate and gellan gum. Cross-linking agents used for the microspheres were aluminum chloride $\left(\mathrm{AlCl}_{3}\right)$ and glutaraldehyde (GA). The evaluation processes of prepared microspheres were carried out by in-vitro release study, swelling index, microscopic analysis, and entrapment efficiency.

Results: All the formulations show good entrapment efficiency and the maximum entrapment $84.6 \%$ was governed by the formulation (F3) crosslinked by $\mathrm{AlCl}_{3}$ and $\mathrm{GA}$ and their obtained mean particle size were $12.46 \pm 3.21 \mu \mathrm{m}$. Release profile of the formulations revealed the sustained design of the drug, particularly this formulation (F3), releasing approximately $40 \%$ over $4 \mathrm{~h}$.

Conclusions: From this experiment, it can be accustomed that F3 possesses higher standard formulation than the rest due to good release profile and entrapment efficiency. Therefore, the long term stability study is required for future development of this formulation.

Keywords: Microspheres, Glimepiride, Gellan gum, Drug release.

(C) 2020 The Authors. Published by Innovare Academic Sciences Pvt Ltd. This is an open access article under the CC BY license (http://creativecommons. org/licenses/by/4. 0/) DOI: http://dx.doi.org/10.22159/ajpcr.2020.v13i5.37229

\section{INTRODUCTION}

Microspheres are solid approximately spherical particles made up of polymeric, waxy, or other protective materials (such as starches, gums, proteins, fats, and waxes) and ideally having a particle size $<200(\mu \mathrm{m})$, which are used as drug delivery matrices for drug delivery. It is a reliable mean of delivering a drug to target a specific site and providing maintenance of desired concentration at that site [1]. There occurs a huge difficulty in research and developmental work of new oral controlled drug delivery systems to target the drugs to particular body parts. For this reason, the drug has to shift the biological membrane, i.e., other organs, tissues, or biological compartment where drug degradation can happen [2]. The colon is selected as the area or sites of interest for the treatment purpose of much disease mainly some inflammatory diseases and colon cancer because it introduces prolonged transit time, decreased proteolytic activity as well as neutral $\mathrm{pH}$, among different organs [3]. Drugs which have permeability and/ or stability issues in the upper gastrointestinal tract, for that colon, become a promising site of drug release [4]. Now different types of synthetic, semi-synthetic, or natural polymers are incorporated in the formulation of controlled drug release systems [5-7].

The main objective of the study was to formulate microspheres by the ionotropic gelation method using gellan gum and sodium alginate with trivalent $\mathrm{Al}^{+3}$ ions as well as covalent cross-linking with glutaraldehyde (GA). Glimepiride was chosen for the sustained release therapy and this drug is having plasma half-life 5-7 h, duration of action $24 \mathrm{~h}$. The drug is administered in a dose of 1-6 mg once or twice a day [8]. Hence, glimepiride is an ideal candidate for the development of sustainedrelease formulation which could result in increased clinical efficacy, decreased frequency of administration, and less side effects.

Glimepiride is an oral hypoglycemic drug which is used in the treatment of type 2 diabetics, but not in type 1 diabetics. It helps to decrease blood glucose levels and is effective orally. It is a second-generation sulfonylurea (KATP Channel blockers) which acts by enhancing Insulin secretion [9]. These kinds of drugs act by blocking the sulfonylurea receptor which is a significant part of ATP-sensitive $\mathrm{K}+$ channel (KATP) in the pancreatic $\beta$ cells membrane. The inward flow of $\mathrm{K}+$ ions is thus reduced or inhibited which may be the cause of reduced intracellular $\mathrm{K}+$ concentration. The cell membrane is partially depolarized, increasing the opening of $\mathrm{Ca}^{2+}$ channel and also the releasing of $\mathrm{Ca}^{2+}$ from intracellular stores. The $\mathrm{Ca}^{2+}$ ions induce the fusion of insulincontaining intracellular granules with the plasma membrane and immediately cause the exocytotic release of insulin.

Gellan gum is a negatively charged exopolysaccharide which is having a high tendency to mix with dissolve in or be wetted by water. It is derived by the aerobic method from bacteria called Sphingomonas elodea. This polymer is comprised of repeated units of glucose, glucuronic acid, and rhamnose in 2:1:1 molecular ratio and two acetyl substituent, acetate and glycerate, linked on glucose residue adjacent of the glucuronic acid [10].

Sodium alginate is derived from alginic acid, a linear copolymer with homopolymeric blocks of (1-4)-linked $\beta$-D-mannuronate (M) and its C-5 epimer $\alpha$-L-guluronate (G) residues, respectively [11].

\section{MATERIALS AND METHODS}

\section{Materials required}

Glimepiride and gellan gum were purchased from Yarrow Chem Pvt. Ltd. Mumbai. Aluminum chlorides $\left(\mathrm{AlCl}_{3}\right)$ were obtained from Loba Chemie, Mumbai. All chemicals and reagents used were of analytical grade.

\section{Methodology}

Preparation of glimepiride microspheres

The glimepiride loaded microspheres were made of sodium alginate and gellan gum. Cross-linking agents used for the microspheres were $\mathrm{AlCl}_{3}$ and GA. Sodium alginate and gellan gum were accurately weighed on a digital balance and dissolved in $15 \mathrm{ml}$ of distilled 
water. The mixture was stirred properly until the polymer mixture becomes bubble-free or uniformly mixed. In a separate beaker, glimepiride was first dissolved in methanol and then dispersed uniformly into $15 \mathrm{ml}$ aqueous dispersion of gellan gum and sodium alginate to form a drug-polymer solution. Then, stirred it properly to get a homogeneous mixture. On a separate beaker, the counter ion solution was prepared by weighing $\mathrm{AlCl}_{3}$ and tween 80 and mixed in $100 \mathrm{ml}$ of water for F1 and F2 and also added GA for F3. The drugpolymer dispersion was added dropwise through flat-tipped needle into slightly agitated $100 \mathrm{ml}$ of $1 \%(\mathrm{w} / \mathrm{v}), 3 \%(\mathrm{w} / \mathrm{v}) \mathrm{AlCl}_{3}$ solution containing $0.08 \%(\mathrm{w} / \mathrm{v})$ Tween 80 , and also in the $3 \%(\mathrm{w} / \mathrm{v}) \mathrm{AlCl}_{3}$ containing $0.08 \%(\mathrm{w} / \mathrm{v})$ Tween 80 and $4.5 \%$ GA. Following an incubation period of $10 \mathrm{~min}$, the microspheres were separated by filtration, washed with double distilled water, and allowed for air-drying. Then, the formulated cross-linked microspheres were withdrawn from the beaker and cleaned them properly by washing with distilled water and make them free from non-reacted GA [12]. The composition of different formulations is shown in Table 1.

\section{Drug entrapment efficiency estimation}

Specified amounts of dried microspheres were properly weighed, crushed with a mortar-pestle, and were taken into the buffer solution. It is kept for a time period so that the time should allow the maximum release of drug from the formulation. Then, the suspension was filtered and sample was taken to be analyzed with a spectrophotometer [13].

\begin{tabular}{ll}
\hline Equation & $\begin{array}{l}\text { Entrapment efficiency }(\%)=(\text { actual drug } \\
\text { content/theoretical drug content }) \times 100\end{array}$ \\
\hline
\end{tabular}

\section{In vitro drug release study}

The paddle-type dissolution test apparatus is useful for the experiment. First, prepared microspheres were properly weighed and taken them in $500 \mathrm{ml}$ buffer solution and temperature of the system was maintained at $37 \pm 0.5^{\circ} \mathrm{C}$. The paddle rotation was fixed at $50 \mathrm{rpm}$. After a specific time interval, a specific amount of aliquot was withdrawn from the dissolution medium and then that volume was replaced by the fresh medium of equal volume. There was no filtration or further dilution. The samples were analyzed using a spectrophotometer [14].

\section{Microsphere size analysis}

Randomly select a specific number of microspheres and their size was measured using an optical microscope. A standard stage micrometer had to calibrate the optical micrometer. The mean diameter was calculated from each batch [15].

\section{Swelling study}

This study is carried out in a buffer solution. A predetermined known weight sample was taken, dissolved into $50 \mathrm{ml}$ buffer media and allowed to swell for a specific time. Then swollen microspheres were periodically removed, blotted with tissue paper and reweighed.

\begin{tabular}{ll}
\hline Equation & $\begin{array}{l}\text { Swelling ratio }=(\text { final weight }- \text { initial weight }) / \text { initial } \\
\text { weight. }\end{array}$ \\
\hline
\end{tabular}

\section{RESULTS AND DISCUSSION}

\section{In vitro release studies}

The USP type II dissolution test apparatus was used for the in vitro drug release study of the prepared glimepiride loaded microspheres. These formulations contain gellan gum and sodium alginate as polymer, counter-ion solutions of $\mathrm{AlCl}_{3}$ and $\mathrm{GA}$ in various ratios as cross-linkers.
From the in vitro release study, it is found that $68.7328 \pm 0.63 \%$ drug release was obtained by the formulation (F1) cross-linked with $1 \%$ $\mathrm{AlCl}_{3}$ followed by $57.4724 \pm 1.32 \%$ release by (F2) cross-linked with $3 \% \mathrm{AlCl}_{3}$, then $40.7098 \pm 1.68 \%$ by (F3) cross-linked with $3 \% \mathrm{AlCl}_{3}$ and $4.5 \% \mathrm{GA}$ over a period of $4 \mathrm{~h}$. The in vitro drug release profile of different formulation is shown in Fig. 1. The extent of drug release varies for different formulations depending on the degree of crosslinking between the ingredients used in each formulation.

It is estimated that the amount of drug released from each formulation over the same period of time decreases gradually with the increase of $\mathrm{AlCl}_{3}$ concentration. The instinctive strength and hydrogel network microspheres can also be modified by the cross-linkage with the use of GA. Further suppression of drug release for the same formulation can be obtained by the GA treatment. The in vitro drug release is decreased to a great extent and the $t_{1 / 2}$ value is comparatively higher for the GA treated microspheres.

\section{Drug entrapment study}

Drug entrapments in the formulations were fairly good, the maximum entrapment being exhibited by the formulation (F1). The formulation (F3) also showed good entrapment efficiency. It can be predicted that the lower entrapment of formulation (F3) might be due to the cross-linking reaction of $\mathrm{AlCl}_{3}$ as well as GA. It is found that the entrapment capability decreases with the increase of $\mathrm{AlCl}_{3}$ concentration in the salt solution as it causes a higher degree of cross-linking. It is thought that more the gelation, greater will be the expulsion of water which is directly responsible for the convective loss of drug molecule from the microspheres during the incubation into the gelation medium. The entrapment efficiency of GA treated microspheres is lower than the untreated ones. The result of drug entrapment study is mentioned in Table 2 .

\section{Average particle size determination}

The size of the particles was measured with the help of an optical microscope taking six particles from each batch. An ocular micrometer was previously attached and the particles were placed on a slide and their size was measured. From the experiment, it is observed that formulation (F1) cross-linked with $1 \% \mathrm{AlCl}_{3}$ is having average particle size $17.23 \pm 1.59 \mu \mathrm{m}$, formulation (F2) cross-linked with $3 \% \mathrm{AlCl}_{3}$ is having average particle size $15.58 \pm 2.67 \mu \mathrm{m}$, and formulation (F3) cross-linked with $3 \% \mathrm{AlCl}_{3}$ and $4.5 \% \mathrm{GA}$ is having average particle size $12.46 \pm 3.21 \mu \mathrm{m}$. It is found that the mean particle size decreases with the increase of $\mathrm{AlCl}_{3}$ concentration in the salt solution. It is thought that more the gelation, greater will be the expulsion of water due to cross-linking. The higher degree of cross-linking causes higher water loss accordingly. The effect of GA on particle size is also important. The

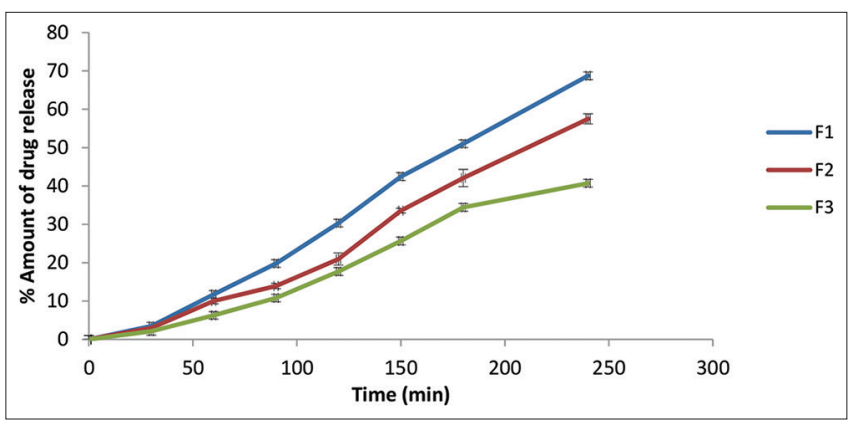

Fig. 1: Release study of glimepiride microsphere

Table 1: Composition of formulation

\begin{tabular}{llllll}
\hline Formulation code & Sodium alginate (mg) & Gellan gum (mg) & Glimepiride (mg) & Aluminum chloride (\%w/v) & Glutaraldehyde (\%w/v) \\
\hline F1 & 250 & 250 & 25 & 1 & - \\
F2 & 250 & 250 & 25 & 3 & - \\
F3 & 250 & 250 & 3 & 4.5 \\
\hline
\end{tabular}


Table 2: \% Entrapment of different batch

\begin{tabular}{ll}
\hline Batch number & \% Entrapped \\
\hline F1 & $84.6 \pm 4.72$ \\
F2 & $81.2 \pm 3.61$ \\
F3 & $78.6 \pm 5.23$ \\
\hline
\end{tabular}

Each value is represented as a mean $\pm \operatorname{SEM}, \mathrm{n}=3$

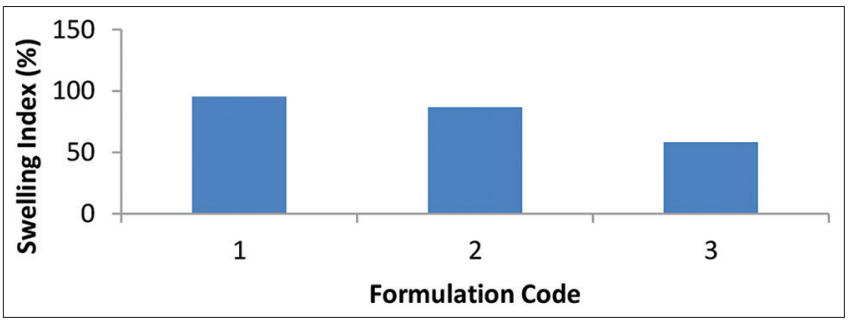

Fig. 2: Swelling indices of various formulations of microspheres

formulation (F3) treated with 4.5\% GA possesses a ridged and uneven surface due to the greater degree of cross-linking of the gelation matrix.

\section{Swelling behavior}

From the swelling study, it is evident that maximum swelling (95.5\%) is exhibited by the formulation (F1) cross-linked with $1 \% \mathrm{AlCl}_{3}$ followed by $86.7 \%$ swelling by (F2) cross-linked with $3 \% \mathrm{AlCl}_{3}$, then $58.3 \%$ by (F3) cross-linked with $3 \% \mathrm{AlCl}_{3}$ and $4.5 \% \mathrm{GA}$. It is also noticeable that the percentage of swelling increased gradually with decreasing concentration of $\mathrm{AlCl}_{3}$. At the same time, the percentage of swelling of the microspheres decreases with the enhancement of the $\mathrm{AlCl}_{3}$ concentration in all types of swelling medium having different $\mathrm{pH}$ value. Estimation found that when $\mathrm{AlCl}_{3}$ concentration was gradually increased to $5 \%$, then the swelling index was reduced to nearly $17 \%$ and GA treatment in those reduced the ratio further by $60 \%$. The result is shown in Fig. 2.

\section{CONCLUSIONS}

Glimepiride is an oral hypoglycemic drug which is prescribed to treat the hyperglycemic condition in the human body by reducing the sugar level. This project was conducted to represent the activity of glimepiride as a model drug by attempting to prolong its release for a longer period of time. To achieve the design of sustained delivery of glimepiride, microspheres were prepared from where the rate of release was reduced by the incorporation of sodium alginate and gellan gum as polymer and $\mathrm{AlCl}_{3}$ and GA served as counterion solutions for cross-linking of the drug. Both sodium alginate and gellan gum have the ability to undergo ionotropic gelation in aqueous solution in the presence of multivalent cations like $\mathrm{Al}^{3+}$. Cross-linking occurs by the formation of covalent bonds between two or more molecules. The cross-linking agents contain two or more reactive ends to chemically attach with functional groups. This phenomenon is known as crosslinking. After the formulation of microspheres, they were evaluated to estimate their microscopy, swelling, yield, and entrapment and release. From this experiment, we have come to know that F3 is a better formulation than the rest formulated. Swelling of F3 was least while the entrapment percent was well. About $78.6 \%$ entrapment efficiency was recorded by the formulation F3. Release profile of the formulations revealed the sustained design of the drug, particularly formulation F3 releasing approximately $40 \%$ over $4 \mathrm{~h}$. This study further assures us the chance and possibility of further development and optimization of the drug taken as a candidate for further investigation.

\section{ACKNOWLEDGMENT}

The authors would like to thank the principal and authority of Netaji Subhas Chandra Bose Institute of Pharmacy, Chakdaha, Nadia, West Bengal, for providing the necessary facilities to perform the present study.

\section{AUTHORS' CONTRIBUTIONS}

Each author is equally contributed.

\section{CONFLICTS OF INTEREST STATEMENT}

There are no conflicts of interest.

\section{AUTHORS' FUNDING}

The authors received no specific funding for this research project work.

\section{REFERENCES}

1. Chandiran IS, Kumar BP, Jayaveera KN. Design and development of microparticulate drug delivery system of Glimepiride for controlled release. Drug Invent Today 2013;5:235-40.

2. Boni FI, Prezotti FG, Cury BS. Gellan gum microspheres crosslinked with trivalent ion: Effect of polymer and crosslinker concentrations on drug release and mucoadhesive properties. Drug Dev Ind Pharm 2016;42:1283-90.

3. Philip AK, Philip B. Colon targeted drug delivery systems: A review on primary and novel approaches. Oman Med J 2010;25:79-87.

4. Friend DR. Colon-specific drug delivery. Adv Drug Deliv Rev 1991;7:149-99.

5. Carbinatto FM, de Castro AD, Cury BS, Magalhaes A, Evangelista RC. Physical properties of pectin-high amylose starch mixtures cross-linked with sodium trimetaphosphate. Int J Pharm 2012;423:281-8.

6. Meneguin AB, Cury BS, Evangelista RC. Films from resistant starchpectin dispersions intended for colonic drug delivery. Carbohydr Polym 2014;99:140-9.

7. Osmałek T, Froelich A, Tasarek S. Application of gellan gum in pharmacy and medicine. Int J Pharm 2014;466:328-40.

8. Tripathi KD. Essentials of Medical Pharmacology. $7^{\text {th }}$ ed. India: Jaypee Brothers Medical Publishers; 2013.

9. Inukai K, Watanabe M, Nakashima Y, Sawa T, Takata N, Tanaka M, et al. Efficacy of glimepiride in Japanese Type 2 diabetic subjects. Diabetes Res Clin Pract 2005;68:250-7.

10. Morrisa ER, Nishinarib K, Rinaudo M. Gelation of gellan-a review. Food Hydrocoll 2012;28:373-411.

11. Liu Z, Lv D, Liu S, Gong J, Wang D, Xiong M, et al. Alginic acidcoated chitosan nanoparticles loaded with legumain DNA vaccine: Effect against breast cancer in mice. PloS One 2013;8:e60190.

12. Maiti S, Ranjit S, Mondol R, Ray S, Sa B. $\mathrm{Al}^{+3}$ ion cross-linked and acetalated gellan hydrogel network beads for prolonged release of glipizide. Carbohydr Polym 2011;85:164-72.

13. Kesharvani S, Jaiswal PK, Mukerjee A, Singh AK. Formulation and evaluation of metformin hydrochloride loaded floating microspheres. Int J Pharm Pharm Sci 2020;12:74-82.

14. Das S, Mondal S. Formulation and in vitro study of ibuprofen loaded cross linked sodium alginate and gellan gum microspheres. Int J Adv Pharm 2017;6:86-90

15. Lal C, Garg R, Gupta GD. Formulation and optimization by applying $3^{2}$ full factorial designs of mucoadhesive microspheres of nifedipine. Asian J Pharm Clin Res 2019;12:321-7. 